\title{
DiOSES EN EL TERRITORIO: IMPLANTACIÓN Y ATRIBUCIONES RURALES DEL PANTEÓN FENICIO
}

Gods in the Territory: Implantation and Rural Attributions of the Phoenician Pantheon

\section{CARMEN ANA PARDO BARRIONUEVO (1)}

Dpto. de Geografía, Historia y Humanidades. Universidad de Almería.cpb868@ual.es

Resumen:

Con este artículo pretendemos dar un nuevo enfoque a los cultos rurales fenicios y al papel que tuvieron en los territorios occidentales. Para ello, desglosaremos los datos sobre iconografía, atribuciones agropecuarias de las principales divinidades fenicias, información del registro arqueológico y veremos las posibles funciones de templos y santuarios. Además, analizaremos la implantación y evolución de estos dioses y su papel durante el proceso de colonización y explotación rural a lo largo del Ir milenio a.C. De manera general, comprobaremos la estrecha vinculación de los cultos con la explotación territorial y las premeditadas advocaciones de los espacios sacros.

Palabras clave: religión fenicia, iconografía, colonización, templos, santuarios.

\section{Abstract:}

In this paper we intend to pay new attention to the Phoenician rural cults and their role in the Western Mediterranean territories. In order to achieve this, we will take advantage from data on iconography, from agricultural attributions of the main Phoenician divinities and from the archeological record. In this way, we will seek potential functions of temples and sanctuaries. In addition, we will analyse the implantation and evolution of these gods and their role during the process of colonization and rural exploitation through the $1^{\text {st }}$ millennium BC. In general, we will verify the close connection between the cults in the territorial exploitation and the deliberate religious associations of these sacred spaces.

Key words: Phoenician religion, iconography, colonization, temples, sanctuaries. 


\section{INTRODUCCIÓN}

Comenzaremos nuestro trabajo definiendo los términos geográficos y cronológicos referentes al ámbito rural fenicio. Como punto de partida, nos gustaría remarcar que coincidimos plenamente con la propuesta de van Dommelen y Gómez Bellard (2008a: 15) sobre los espacios rurales donde se incluirían, de manera general, toda actividad antrópica alejada espacialmente de los grandes núcleos urbanos; es decir, comprenderemos los territorios de las explotaciones agrícolas, pero también de los enclaves marítimos o pesqueros.

Por otro lado, aunque nos centraremos en los territorios fenicios del Mediterráneo central y occidental, también nos remitiremos, siempre que sea conveniente, a los datos de las ciudades próximo-orientales. Finalmente, la acotación cronológica estará comprendida principalmente en el I milenio a.C. aunque de nuevo, cuando sea procedente, rebasaremos los límites de esta horquilla temporal. Esta amplitud nos permitirá esbozar una primera aproximación a la evolución general de la religión rural fenicia, aunque, obviamente, somos conscientes de las particularidades y vicisitudes de cada territorio fenicio y los tendremos en cuenta cuando los estudios lo permitan. Sin embargo, debemos advertir que la mayor parte de la documentación de los lugares de culto procede de prospecciones superficiales donde no se ha podido establecer una cronología clara o exacta, ni mucho menos una atribución cultual.

Pese a estas limitaciones, el principal objetivo de nuestra investigación sería llamar la atención sobre la importancia de las atribuciones rurales de los dioses y diosas en los diferentes territorios y ofrecer una explicación plausible sobre las advocaciones según el contexto geográfico y cronológico no siendo azarosa la divinidad escogida para tutelar estos lugares de culto. También sabemos que se trata de una labor prácticamente imposible intentar separar las prácticas religiosas de la vida cotidiana, o de los aspectos políticos o económicos en las sociedades antiguas. Los fenicios, habitualmente asociados al comercio y a la vida urbana, no constituyen en absoluto una excepción a esta regla. Es más, la religión fenicia estuvo estrechamente vinculada con la explotación rural y con los ciclos agrícolas de los principales cultivos. No en vano, los dioses principales de esta cultura de origen próximo oriental presentaban atributos directa o indirectamente relacionados con el territorio o la explotación de éste. Tampoco es sencillo separar los rituales y prácticas religiosas urbanas y rurales ya que no existirían diferencias consistentes (North 1995: 146-147). Sin embargo, es fácil evocar las figuras de Astarté y de Tinnit como las patronas más presentes en los cultos rurales occidentales, aunque, como veremos, estas diosas no sólo formaron parte de los cultos rurales ni tuvieron la exclusividad de las tutelas, aunque sí parecen tener un marcado predominio sobre otras divinidades.

Así, la religión fenicia influyó en gran parte de los aspectos de la vida cotidiana y arrastró fuertes connotaciones de una sociedad, en origen, eminentemente agrícola. La propia distribución del tiempo estaba marcada por fiestas que se relacionaban mayoritariamente con procesos agrícolas. Aunque no se trataría de un calendario propiamente fenicio, las inscripciones de Karatepe nos sirven para ilustrar esta idea ya que se mencionan tres grandes celebraciones: la fiesta del año nuevo (zbh ymm), la fiesta de la recolección ( $t h r \breve{s}$ ) y la fiesta de la vendimia ('t qșr) (Lipiński 1993: 257).

Pese a toda esta información, los cultos rurales, o más bien la importancia de las atribuciones agropecuarias de los dioses venerados por los fenicios, han pasado tradicionalmente desapercibidas en los estudios religiosos. Además, podemos advertir una desconexión entre los estudios iconográficos de las representaciones figuradas y el contexto territorial y cronológico de los espacios sacros. En Occidente, sabemos que el sistema religioso fenicio evolucionó y se adaptó a las necesidades de cada territorio. También, los dioses locales adoptaron o absorbieron características y atribuciones de otras divinidades en un proceso de reelaboración doctrinal donde la teología y la mitología sufrieron una reinterpretación por parte de la élite sacerdotal (Ribichini 2008: 280) que configuró un nuevo orden religioso en el occidente fenicio.

\section{LA EVOLUCIÓN RELIGIOSA DE LOS TERRITO- RIOS FENICIOS OCCIDENTALES}

Aunque no podemos generalizar una evolución conjunta de los territorios fenicios occidentales, la realización de tablas y planos diacrónicos nos ha servido para comprobar cómo ya desde el inicio de la colonización se emprendió la sacralización de las costas a través de santuarios claramente reconocibles desde el mar (fig. 1). Esto propició, además, que sirvieran como mecanismo de orientación, para las frecuentaciones marítimas y garantizaba la continuidad y seguridad de este tipo de rutas (Ruiz de Arbulo 1997: 521). En el interior, la posición 


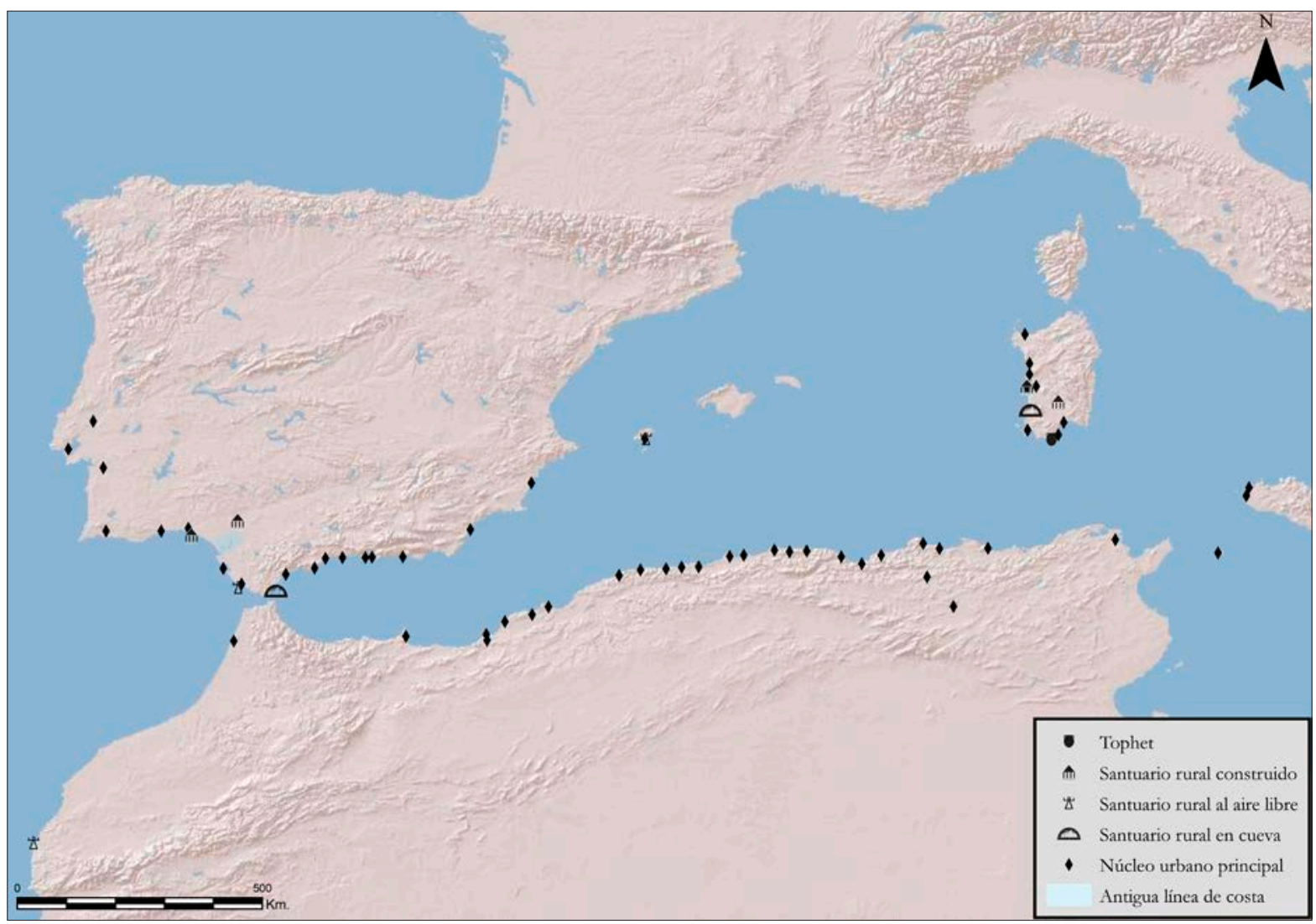

Fig. 1: Poleis fenicias y lugares de culto extraurbanos durante los ss. IX-VII a.C.

preeminente de los lugares de culto le permitía el control de las principales vías de comunicación, de la costa, de las khoras de los núcleos urbanos... lo que en conjunto, favoreció la estabilidad económica y social. Por otra parte, debido a que eran un elemento fácilmente reconocible en el paisaje, servían para marcar el inicio o el fin de un territorio (Bonnet 1988: 141, 345-346, 409 y 433; Angás 2005: 69 y 89). Finalmente, la naturaleza divina de estos espacios les confería un carácter neutral que permitía su uso tanto a otros navegantes como a poblaciones próximas autóctonas (Berchem 1967: 76).

Otro punto de inflexión podría establecerse en el s. V a.C. (fig. 2), coincidiendo con el inicio de la explotación sistemática del territorio (van Dommelen y Gómez Bellard 2008a: 6; Pardo 2015: 85). Especialmente significativos en este proceso serían los territorios de Ibiza, Túnez y Cerdeña donde la contemporaneidad de los lugares de culto en el territorio y los asentamientos rurales implicaría que ambos se integraran como parte de la expansión rural (van Dommelen y López Bertrán 2013: 293; Cruccas 2015 :
93-94). En Cerdeña, además, gracias a un estudio más exhaustivo, podemos observar varias estrategias de explotación del territorio y establecimiento de lugares de culto dependiendo de las condiciones edáficas, orográficas y de población precedentes: en el territorio de Neápolis, por ejemplo, encontraríamos una alta densidad de pequeños asentamientos rurales; en Nora y Monte Sirai, el territorio estaría altamente jerarquizado (van Dommelen 2006: 14; van Dommelen y Finocchi 2008: 198-200; van Dommelen y Gómez Bellard 2008b: 217 y 227); en la península del Sinis, los asentamientos rurales tendrían su propio espacio sacro asociado y se reutilizarían algunos nuraghi; mientras que en la zona de Gesturi, Sanluri y Trexenta, la interacción con los autóctonos en la explotación rural y en la instalación de lugares de culto sería sistemática y la reutilización de nuraghi sería habitual (Roppa 2013: 98).

Finalmente, podemos registrar el cénit máximo de la implantación de cultos rurales en el Mediterráneo occidental durante los ss. IV y II a.C. (fig. 3). Es entonces 


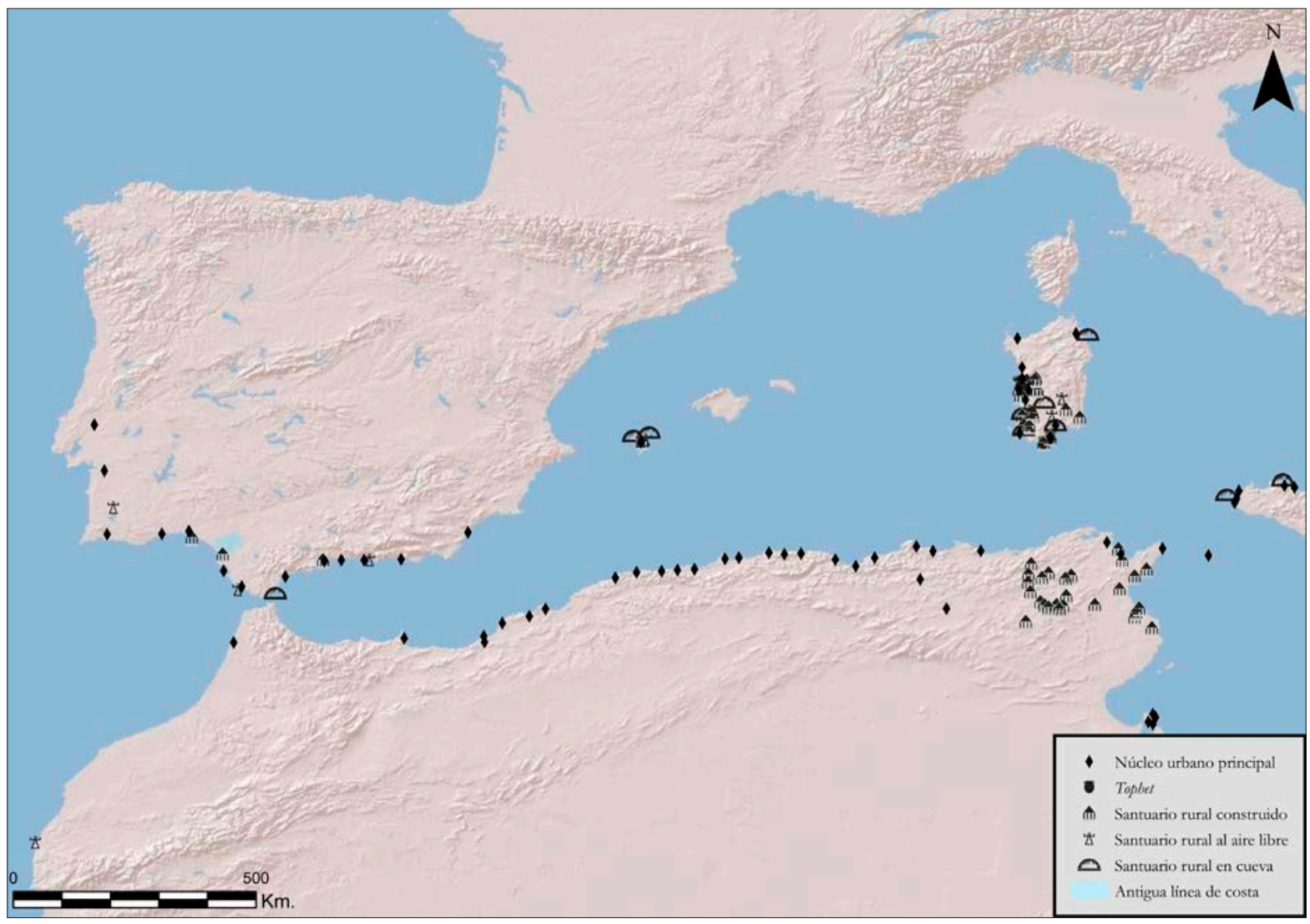

Fig. 2: Poleis fenicias y lugares de culto extraurbanos durante los ss. VI-V a.C.

cuando registramos una gran variedad y presencia de lugares sacros: santuarios al aire libre o construidos, cuevas-santuario, tophet en espacios rurales, y monumentos turriformes. Podemos comprobar cómo prácticamente todos los territorios fenicios cuentan al menos con uno o dos lugares de culto rurales y continúa la tendencia de la etapa anterior donde los territorios más densificados estarían en el Mediterráneo central e Ibiza. En esta última isla, el alto número de lugares de culto ha contribuido a pensar que cada núcleo rural ebusitano podría estar asociado a una pequeña instalación cultual a cierta distancia de la zona de hábitat (Ramon 1995: 53).

Es en estas fechas cuando se observa de una manera más clara que la ubicación de estos lugares de culto permitió marcar el fin o el inicio de un territorio. Debemos buscar el origen del santuario como lugar de "frontera" o de los "confines" en Palestina a finales del s. X a.C. Fue entonces cuando la dinámica comercial requería un elemento físico de indicación de los límites del territorio y, a la vez, un lugar de encuentro entre las poblaciones
(Oggiano 2005: 125). El mejor ejemplo sería Cerro Tortuga, y al igual que Cerro Montroy, pudo funcionar como santuario extraurbano ligado a las relaciones entre fenicios y autóctonos. Además, estaría vinculado con el control de los valles del Guadalmedina y el Guadalhorce como principales vías de comunicación entre Malaka y el interior bético (López Castro y Mora Serrano 2002: 191) y serviría como indicador de frontera (Ferrer Albelda 2014: 222).

En el $\mathrm{N}$ de África, fueron de especial relevancia para la frontera los tophet, y aunque comenzaron siendo lugares de culto periurbanos ligados a las instituciones públicas (Melchiorri 2010: 511-512; Xella 2012-2013: 262; Bernardini 2012-2013: 9 y 11), a partir del s. IV a.C. se asocian a enclaves no urbanos fruto de la expansión cartaginesa de estos siglos (Ruiz Cabrero y Peña 2010: 464). A ello debemos unir como indicadores del territorio, límite fronterizo o final de la jurisdicción de una ciudad, los monumentos turriformes en el $\mathrm{N}$ de África cuando, a partir del s. IV a.C., estuvieron cargados de un enorme 


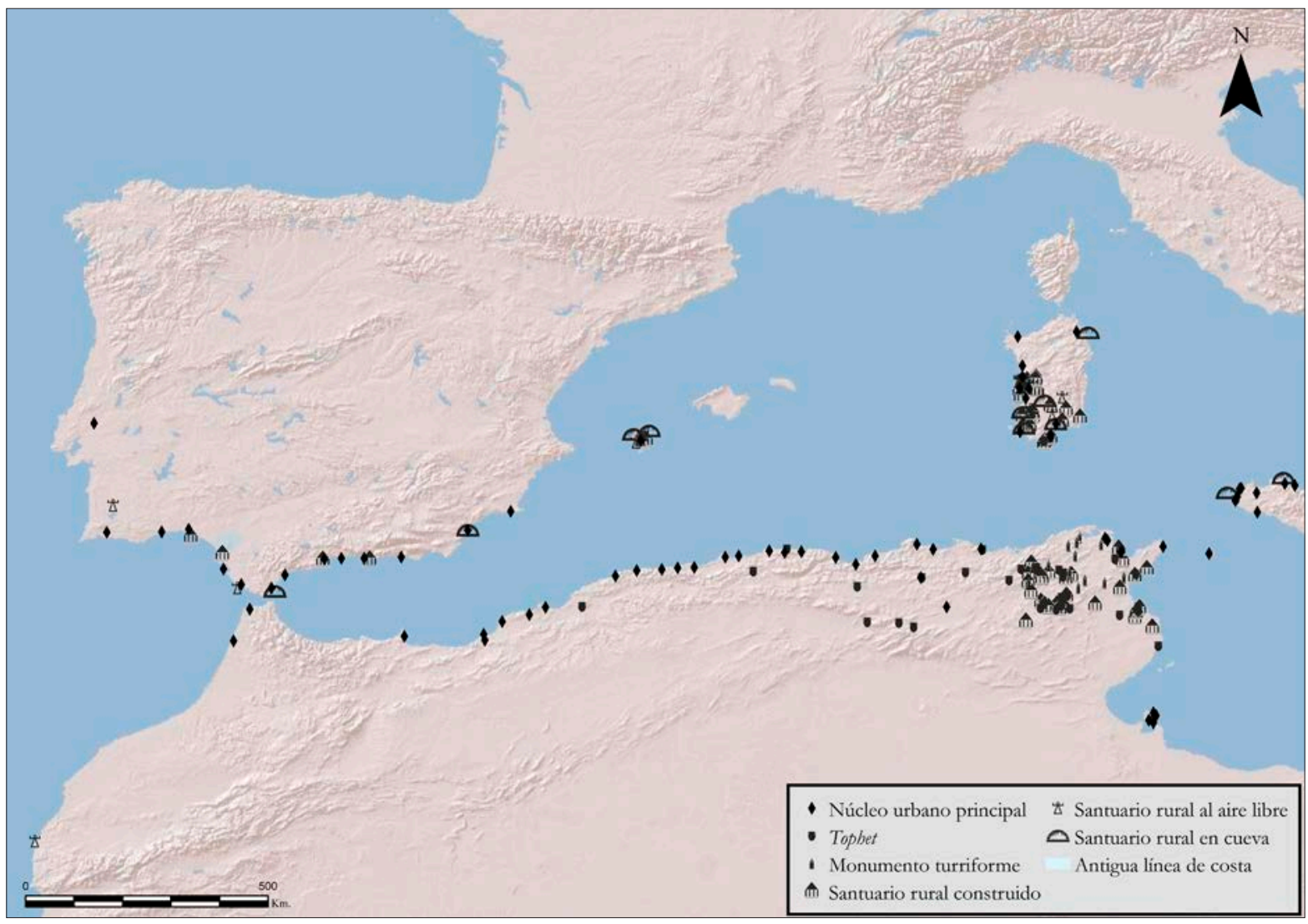

Fig. 3: Poleis fenicias y lugares de culto extraurbanos durante los ss. IV-II a.C.

simbolismo y heroicidad cultual (Prados 2008: 141, 198 y 210-211). Así, es significativa la coincidencia entre las fronteras de los distritos diferenciados por Manfredi (2003) en el territorio de Cartago entre los ss. IV y II a.C. con la situación de la mayor parte de los lugares sagrados. Especialmente remarcables son los límites entre Gunzuzi y Zeugei, entre Gunzuzi y Thuscae, o entre Gurza y Bizacena. En otros casos, como la frontera entre Muxi y Zeugei, los hitos fronterizos pudieron ser necrópolis rurales en lugar de santuarios (fig. 4).

\section{ADVOCACIONES DE LOS CULTOS RURALES FENICIOS OCCIDENTALES}

Una característica de los dioses fenicios, tanto en Oriente como en Occidente, es la ausencia de tríadas en los templos, como máximo se rendiría culto a una pareja divina cuyo elemento más sólido sería una diosa de carácter universal (Xella 1986: 33-34). Así, los principios de masculino-femenino acompañan el simbolismo de las parejas divinas: el dios representa la fertilidad y la diosa la fecundidad (Lipiński 1995: 65). Sin embargo, en la mayoría de los casos desconocemos el culto desarrollado o tenemos una vaga atribución como "culto a la fertilidad", "culto al agua" o "culto de divinidad salutífera" (vid. fig. 7). No obstante, podemos advertir una significativa presencia de Astarté y Tinnit quienes tuvieron un papel fundamental en la religiosidad rural del interior del territorio destinado a la explotación agropecuaria (Grotanelli 1981: 115; van Dommelen y Gómez Bellard 2008b: 210 y 227-229). Ambas diosas suman más del $15 \%$ de las advocaciones determinadas en los lugares de culto rurales sin tener en cuenta los casos en que se han identificado cultos agrícolas atribuidos a Deméter/Koré cuya problemática abordaremos más adelante.

En las costas orientales, Astarté era la diosa encargada de proporcionar el vino y esporádicamente aparece en los textos administrativos de Ugarit el término "el lagar de Astarté". No en vano, esta diosa contaba con unas importantes 


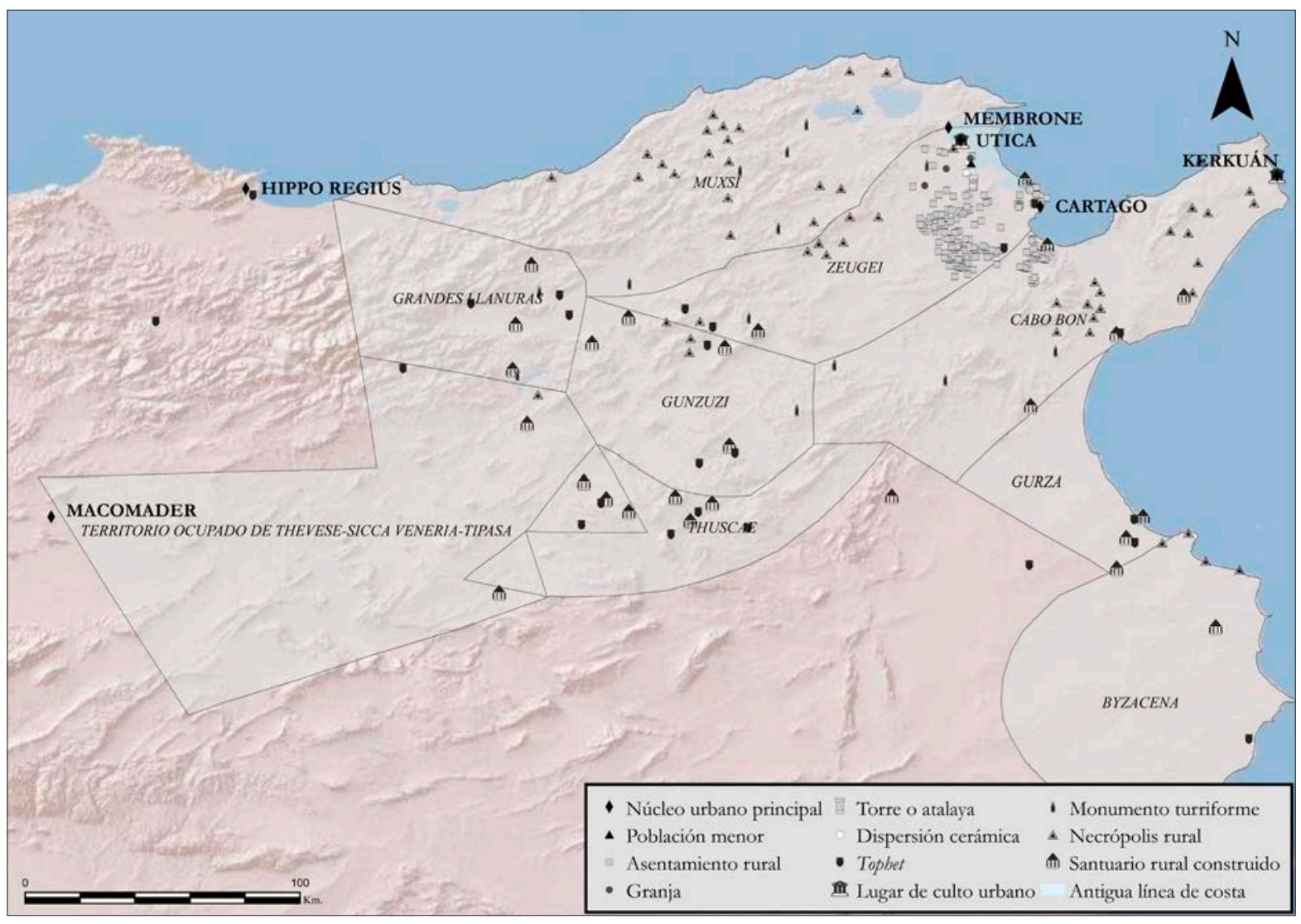

Fig. 4: Distritos de Cartago a partir de Manfredi 2003 y principales yacimientos en el NO de África durante los ss. IV-II a.C.

fiestas en su honor relacionadas con la vendimia celebradas en "los comienzos del vino" o "primicias del vino" quizás coincidiendo con la apertura del año ugarítico (septiembre u octubre) (Zamora 2000: 61, 209 y 229230; 2005: 80). Junto con Shagar, era la protectora del ganado (Hvidberg-Hansen 1986: 171-172) y es denominada "Astarté de los rebaños" o "Astarté del campo" en el Antiguo Testamento (Deut. 7-13) en clara alusión a su influencia sobre la fertilidad de la tierra y de los animales (Delcor 1976: 89-92). Estaba ligada de manera particular a la caza sagrada practicada como rito de fertilidad como parecen demostrar sus bronces donde aparece armada, símbolo de la guerra y la caza (Lipiński 1995: 131-132 y 153-154; Bonnet 1996: 143, 150 y 152). Estos atributos se ven corroborados por el análisis de la fauna de los lugares de culto bajo advocación de Astarté donde la mayor parte de animales sacrificados serían ovinos y caprinos y habría una representación considerable de animales salvajes, sobre todo ciervos (Pardo e.p). Además, su amplio espectro de intervención (fecundidad, bienestar, guerra, navegación, más allá...) (Bonnet 1996: 97, 108 y 151; Amadasi Guzzo 2010: 465) favorecieron que a partir del I milenio a.C., Astarté relegara al resto de diosas semíticas y fuera considerada como diosa suprema de los fenicios (Lipiński 1995: 131-132), poliada y protectora del rey por antonomasia (Bonnet 1996: 97).

Los atributos de Astarté, y como consecuencia sus representaciones, variaron dependiendo de la zona. Por ejemplo, en Eryx Astarté tenía como símbolo la paloma (Lipiński 1995: 153-154), no obstante, algunas terracotas zoomorfas de colúmbidas documentadas en contextos fenicios occidentales pudieron pertenecer tanto al culto de Astarté como al de Tinnit (Horn 2011: 285) o, incluso injerencias de Deméter o Koré (van Dommelen y López Bertrán 2013: 276).

Para exponer someramente la problemática entre las divinidades femeninas occidentales y los datos que tenemos sobre las relaciones entre Tinnit y Astarté usaremos algunos ejemplos donde aparecen documentados estos vínculos. Tinnit pudo ser una hipóstasis de Astarté en 
Sarepta, Cartago y ocasionalmente en Malta. Tampoco es del todo elocuente la inscripción del santuario rural en Deir el-Qal'a (Líbano) fechada entre los ss. II y III d.C. Se trata de un texto bilingüe latín-griego donde se menciona a Hera la cadete o Hera menor (Ibus S[imae]) junto a Baal y Juno. Esta inscripción podría indicar los lazos entre Tinnit y Astarté donde Tinnit sería Hera NeotecaCaelestis-Nephthys y Astarté, Hera-Juno-Isis. Por tanto, si se copió el modelo egipcio conceptual teológico de las parejas divinas, Isis sería hermana de Nephthys, es decir, su hermana menor (Bonnet 1991: 74, 80 y 83). Las mayores dificultades para su identificación se presentan en Cartago donde sabemos, a partir de una inscripción (CIS I, 3914; Rès 17, Kai 81), que en Cartago existía un santuario para Tinnit y otro para Astarté ambos en estrecha relación (Lancelloti 2010: 26). De hecho, compartieron propiedades, aunque fue finalmente Tinnit la que heredó la dimensión poliada característica de Astarté en oriente (Bonnet 1996: 108 y 151) y algunos elementos esenciales de Anat y Athirat confluyeron en Astarté (Xella 1982: 68) y Tinnit (Hvidberg-Hansen 1986: 186-187).

Ambas diosas, Astarté y Tinnit, tuvieron una gran aceptación entre las culturas autóctonas en contacto con pobladores fenicios y se superpusieron a otras figuras locales preexistentes y con las que pudieron identificarse (Hvidberg-Hansen 1986: 186-187; Amadasi Guzzo 2010 : 65). Sus representaciones tuvieron una gran difusión en el Mediterráneo, sobre todo a partir del s. V a.C. En el caso concreto del mundo íbero, las terracotas no responderían a las figuras de Deméter o Astarté, sino que serían la representación de una divinidad autóctona que habría adquirido los atributos de estas diosas foráneas, lo que no implicaba que se adoptara el culto en sí (Domínguez Monedero 1995: 77-78 y 83). También en Cerdeña desde el s. V, pero sobre todo en el III a.C., comenzaron a diversificarse los cultos de manera local en los espacios rurales; especialmente remarcables serían las terracotas con atributos propios de Deméter quizás debido a sus ámbitos de actuación en las necesidades inmediatas de la población: maternidad, protección ante las enfermedades y fertilidad del suelo (van Dommelen y López Bertrán 2013: 275; Garbati 2014-2015: 82, 116-117). Más polémica es la presencia de la diosa griega Deméter en la propia Cartago (Garbati 2008: 73). Sin embargo, la ausencia de antropónimos atestiguados con las raíces de Demeter o Koré, podría indicar que su culto no estuvo introducido en la capital norteafricana. A ello habría que unir que todas las atribuciones de esta diosa relacionadas con la agricultura y la fertilidad confluirían en Tinnit y no habría necesidad de otro culto exógeno (Fantar 2008: 245-246).

En cualquier caso, los pebeteros de cabeza femenina han sido identificados comúnmente con una diosa chtoniana, con una doble vertiente: por un lado, promover la fecundidad y, por otro lado, la fertilidad de los campos (Garbati 2008: 62). Por ello, en contextos cultuales púnicos, sería razonable pensar que esta diosa fuera Tinnit (Horn 2011: 54, 64 y 124). Sin embargo, incluso en los propios santuarios rurales fenicios no es fácil hacer una asociación entre las representaciones femeninas en terracota y una diosa concreta. Un buen ejemplo sería el

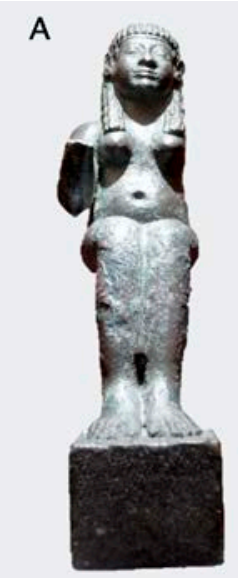

B

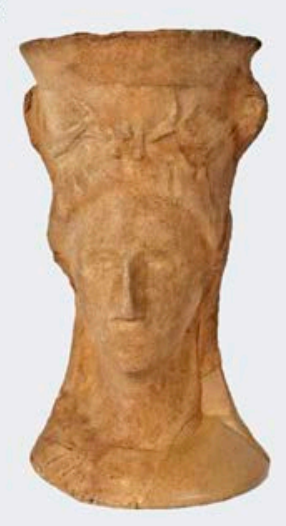

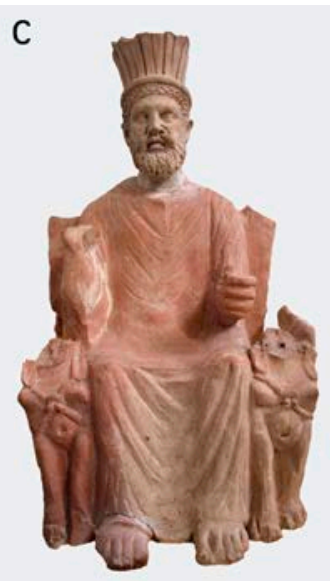

D
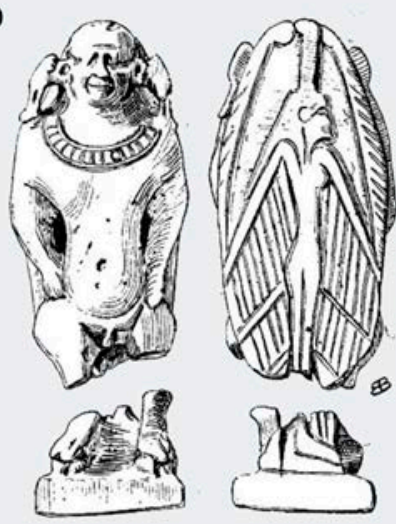

Fig. 5: A. Astarté (VIII-VII a.C., Carambolo, SP). B. Tinnit (III a.C., Cerro Montroy, SP). C. Baal Hammon (I a.C., Thinissut, TN). D. Eshmun de Sidón (Contenau 1924: 21, fig. 15). 
santuario de La Algaida, perteneciente al territorio de Gadir, frecuentado desde el s. VI a.C. y dedicado al culto de Astarté. En este caso, las primeras estructuras fechadas en el s. IV a.C., también coincidirían con el proceso de asimilación de Astarté con Tinnit (Ferrer Albelda 2002: 199 y 201-202; 2017: 222). Incluso, en casos donde parece una advocación clara, como la cueva-santuario de Cerro Montroy en Baria consagrada a Tinnit (fig. 5, b), se han identificado algunas terracotas masculinas como Bes y Melqart (López Castro 2001-2002: 79-80, 82, 84 y 86).

Más complejo aún sería el caso Es Culleram cuyo uso pudo remontarse a las últimas décadas del s. V e inicios del IV a.C. (Marín Ceballos et al. 2010: 153). Esta cueva, tradicionalmente adscrita al culto exclusivo de Tinnit por la documentación de numerosas figuras antropomorfas que portaban en las manos palomas, cerdos, granadas o cervatillos (Aubet 1969: 28-29, 31-32, 52, 60-61 y 65-66; Marín Ceballos et al. 2010: 149) ha sido recientemente cuestionada. Así, aunque se acepta que en su fase más antigua estuviera dedicada a Tinnit, en un momento impreciso del s. IV a.C. pudo introducirse un nuevo culto a Deméter con la que compartiría rituales y cuyo testimonio, precisamente, serían las terracotas femeninas representadas con kalathos, un velo, antorchas, lechones y bebés (van Dommelen y López Bertrán 2013: 284; Marín Ceballos et al. 2015: 208209 y 213).

Indisolublemente unido a Tinnit sería el signo con que se identifica. Su origen es independiente al de la propia diosa, aunque a menudo ambos estuvieron asociados. Debido a su presencia en contextos de sacrificio humano o animal con el fin de regenerar las fuerzas sagradas de la fecundidad presentes en la cosecha, se ha pensado que su simbología procedería de la evolución del símbolo egipcio 'ankh cuyo significado, "vida", podrían compartir (Lipiński 1995: 205-206 y 214). Otros autores (Tejera y Chávez 2010: 300 y 307-309), en cambio, consideran que sería la esquematización del dios Baal. Entre sus representaciones figuradas, Tinnit porta alas cuando simboliza la protección de la ciudad. Además, su iconografía en las monedas pudo servir para implantar nuevos cultos en comunidades autóctonas a través de la iconografía y, actualmente, sirve para determinar cuáles fueron los agentes de tal aculturación (García Bellido 1991: 42 y 55). Por otra parte, pudo aunar la simbología de la vida, la fecundidad, la prosperidad y la fertilidad y podría atribuírsele un poder propiciatorio y/o profiláctico y la aptitud de operar en sinergia (Ferrer Albelda 2015: 176). Su iconografía relacionada con la fecundidad es variada y numerosa, aunque normalmente se trata de motivos vegetales como palmas, espigas, granadas, palmeras, olivos, ramas de árboles, etc. (Hours-Miedan 1951: 24, 46, 47, 61 y 70; Lancellotti 2010: 107-109). Por su parte, la distribución geográfica del culto a Tinnit abarcaría todo el Mediterráneo fenicio, aunque normalmente está asociado a Cartago donde se alzó como la Diosa-Madre promotora del Genius Terrae Africae y acabó asimilándose a la diosa Ops, a la diosa Nutrix (Lipiński 1995: 200, 202203 y 205) y, en último término a Iunno Caelestis (Xella 1991: 90), diosa que también recibiría parte de los atributos de Astarté (Lancellotti 2010: 21-22 y 69).

Un epíteto habitual de Tinnit en las inscripciones del tophet de Cartago es la de "plañidera en frente de Baal" $\left(P n B^{\prime} l\right)$. Era la encargada de hacer renacer periódicamente a Baal Hammon en una tierra renovada y ambos cultos estaban ligados al ritual agrario de tipo sacrificial del molk. Aunque los tophets deben ser considerados un fenómeno relacionado con la complejidad urbana de determinados centros en época arcaica típico de la colonización fenicia (Melchiorri 2010: 511-512), su ubicación sirve como punto de referencia de otros centros menores dependientes de la ciudad (Xella 2012-2013: 262) y de conexión ideológica con la población (Bernardini 20122013: 9 y 11). Además, el propio rito $m l k$ estuvo ligado intrínsecamente a rituales agrarios de fertilidad (Lipiński 1995: 260-264, 380-382, 478 y 481), y a partir del s. IV y hasta el s. I a.C., la instalación de los tophets en el $\mathrm{N}$ de África, parece estar de alguna manera vinculados directamente con la explotación rural (Ruiz Cabrero y Peña 2010: 464) y, en algunos casos, estarían situados en la frontera entre distritos (vid. fig. 3). A ello contribuirían las atribuciones del propio Baal como dios agrícola por excelencia (Moret 1935: 329; Bonnet 1996: 143, 150 y 152) pero también del comercio, de la navegación y de la expansión colonial (Xella 2001b: 91). El propio mito de la muerte de Baal estaría asociado al olivo y a otros frutos de la tierra (Xella 2001b: 77 y 81), y tendría poder sobre la lluvia, las aguas, las fuentes, las crecidas, la germinación y el crecimiento de los cereales (Xella 1982: 58, 61 y 65; Lipiński 1995: 65). Baal Hammon, en sus representaciones figuradas en el $\mathrm{N}$ de África aparece sentado en un trono o de pie con una especie de cetro con una o tres espigas de trigo en la mano izquierda (fig. 5c) (Xella 1991: 129; Lipiński 1995: 262). Parece muy probable que Plutón el Africano (interpretatio de Baal Hammon) heredara las cualidades del dios fenicio en las atribuciones de "dispensador de la prosperidad" o "fuente de 
bendiciones", patrón de los enfermos y señor de la fertilidad agraria (Ribichini 1986: 133). Más complicado es el apodo latino de frugifer, que podría provenir de Baal Addir como un epíteto o una manifestación particular de Baal Hammón y significar "poderoso" (Xella 1991: 67). Otros autores (Lipiński 1995: 261 y 380-382), sin embargo, consideran que frugifer sería algo así como "acumulador de trigo" o "cosechas", y estaría estrechamente vinculado con la fecundidad y la riqueza a la que se dirige la piedad de los africanos, dios de la agricultura y dueño del inframundo con influencia en la regeneración vegetal.

En los textos de Ram Shamra en Hadad, Baal aparece como hijo de Dagan, dios de la fertilidad y la vegetación. Además, Baal sería el señor de los campos cultivados ( $B$ ' $l$

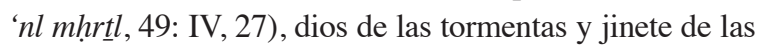
nubes. Su relación con el territorio está presente en la expresión fenicia de "terreno de Baal" o "regado por Baal". Esta fórmula se aplicaría a todo aquel terreno fecundado por la naturaleza o por el dios de la naturaleza y se opondría al ser humano y su industria. Así, deben incluirse también las fuentes naturales que hacen fecunda la tierra (Lagrange 1905: 97-98; Dussaud 1921: 206; Smith 1927: 97). Por sus atributos celestes, en el templo de Baal era de obligado cumplimiento la construcción de una ventana por la que se comunicaba el dios con la tierra (Xella 1982: 72), y por la que pasaba la lluvia y cuya representación ritual pudo ser la libación (Delcor 1970: 122-124 y 129), originalmente un rito agrario de fertilidad cananeo celebrado en otoño destinado a la obtención de lluvia (Dussaud 1921: 205206). Este atributo se mantuvo en época tardía como atestigua una de las inscripciones del santuario rural de Deir el-Qal'a (Líbano) fechado entre los ss. II y III d.C. donde se menciona un santuario dedicado a Baal Marqod con el epíteto mēgrin. Este calificativo pudo derivar del semítico grn, tormenta, y confirmaría su lazo con la agricultura, la fertilidad y las danzas (Servais-Soyez 1986: 352; Bonnet 1991: 73 y 76). Además, la liturgia de los profetas realizada a Baal en la cima del monte Carmelo (I Re XVIII, 25) ha sido interpretada como un ritual de fertilidad al igual que lo sería el cántico y la danza de David frente a la ventana de Mical (II Sam VI). En ambos casos, se trataría de un ritual de fecundidad proveniente de Canaan de origen campesino como agradecimiento a la fecundidad, a la fertilidad y a la victoria (Caquot 1963: 127-128 y 137-138). Sin embargo, pese a esta evidente relación con la tierra y excluyendo la exclusividad que presenta junto a Tinnit en los tophet, no se ha constado con seguridad ${ }^{1}$ ningún templo dedicado a Baal fuera del ámbito urbano.
Melqart, por su parte, además de en numerosos templos urbanos (Bernardini 2012-2013: 3 y 7; Mora Serrano 2013) y su posible culto en Antas, únicamente se ha identificado en ámbito rural en el santuario costero de Grotta del Pozzo usada entre el s. IV a.C. y el II d.C. donde fueron documentados varios testimonios epigráficos y figurativos (Rocco 1972). Pese a que Melqart en el Mediterráneo Occidental ha sido relacionado con las etapas de navegación en el Mediterráneo (Ribichini 2008: 299), el resto de santuarios litorales presentan una difícil adscripción como el abrigo costero de $\mathrm{Sa}$ Cova des Vi (Ses Fontanelles), situado entre la Bahía de Sant Antoni y Cap Nunó en Ibiza (Breuil 1920: 370; Beltrán et al. 1987).

Sin embargo, al igual que Baal, el peso de Melqart en el territorio no sólo debe entenderse por la cantidad de santuarios bajo sus advocaciones, sino que ambos estuvieron estrechamente ligados a la justificación de la apropiación de un territorio durante la colonización fenicia (Berchem 1967: 76; Xella 2001b: 91; Arruda y Celestino Pérez 2009: 45; Bernardini 2012-2013: 10; Garbati 20122013: 53). Melqart ostenta el título de jefe del ejército que coloniza y civiliza, purifica, apacigua y defiende frente al peligro, su propia vida sería un excelente ejemplo de hégémon en las nuevas ciudades (Diod. IV, 17, 4-5; IV, 18, 1; IV, 19, 1-4; IV, 22, 2-3; IV, 24, 3-7; IV, 27-3). También, el apodo de este dios, "el de la roca" (' $l$ $h s r$ ), posee un doble significado: los cimientos y la fundación del enclave (Bonnet 2008: 676) cuyas atribuciones de dios poliado y dinástico, asociado a la fertilidad y al orden están relacionados con los intereses tirios en su expansión colonial hacia Occidente (Bunnens 1986: 121122; Jourdain-Annequin 1992: 277-278; Bonnet 2005: 20). Precisamente, todas estas características han justificado la difícil asimilación de esta divinidad en las culturas locales (Amadasi Guzzo 2010: 65-66; Bernardini 2012-2013: 6-7) y su preminencia en templos urbanos y no así en ámbitos rurales.

También nos encontramos con problemáticas advocaciones masculinas en santuarios rurales. La que más literatura científica ha generado sería el santuario rural de Antas. La importancia de este santuario radicaría en su imponente monumentalización a partir del s. IV a.C., y la gran cantidad de ofrendas, algunas de ellas de personas con altos cargos (Barreca 1969: 36-37; Zucca 1989: 3738). Aunque sabemos que en época romana el templo estaba consagrado a Sardus Pater, quizás como adaptación de un culto autóctono anterior (Sardus Babbai) 
(Grotanelli 1981: 111), o quizás como modo de congraciarse con la población recién conquistada, en época anterior no podemos asegurar con certeza la figura de ningún dios principal (Roobaert 1986: 336-337). Tradicionalmente, el culto prerromano parece estar asociado al dios Sid, un dios de origen egipcio cuyo culto no ha sido constatado con certeza en Oriente (Lipiński 1995: 332, 338 y 343) y el cual a partir de la etimología de su nombre ( $s d=$ cazar), podemos extraer que sería un dios cazador o pescador (Roobaert 1986: 339; Bonnet 1988: 263). Su simbología, relacionada con el "santo pilar-djed" o $\underline{d} d$ spśi, sería el dios "Padre" que "da la vida" (Lipiński 1995: 350). También se ha planteado que pudiera (co) existir el culto a Melqart (Amadasi Guzzo 2005: 15) o incluso un único culto a Baal Hammon a partir de la estatua de Genoni (Roobaert 1986: 340-345). En cualquier caso, unido a la posición del templo respecto al territorio, el control que ejercería sobre la zona del Iglesiente, y su consagración principal a algún dios relacionado con los recursos naturales, abogan por un culto relacionado directamente con la explotación rural.

Un caso particular sobre la relación entre dioses y territorio sería el de Sidón según se desprende de la inscripción de Eshmun azor II fechada a principios del s. V a.C. En ella, se diferencian dos zonas sagradas: una perteneciente a la polis, Sidón "del mar", custodiada por Baal poliado, y otra en la chora, Sidón "de la llanura", donde Eshmun era venerado cerca de la fuente de Ydal (fig. 5, d; Bonnet 1988: 96). También en Biblos, el dios principal de la agricultura sería Eshmun (Moret 1935: 339). Sin embargo, debido a su particular leyenda, Eshmun no muere y resucita como otros dioses fenicios por lo que la fertilidad o la fecundidad no entraría dentro de sus ámbitos de actuación (Xella 2001a: 368).

En occidente, a Eshmun o Bes, como dioses relacionados con la sanación, podrían atribuírseles algunos de los santuarios rurales con exvotos alusivos a la salud. Sin embargo, nuevamente, contamos sólo con un ejemplo y además tardío sobre la presencia de Eshmun en territorio fenicio occidental. Se trataría del santuario de Santu (San Nicolò Gerrei) registrado en 1861 donde fueron documentadas una estructura rectangular de mampuesto seco y una basa de columna con una triple inscripción en fenicio, latín y griego fechada en el s. II a.C. dedicada a Eshmun Merre (traducido como Asclepios o Esculapio en la versión griega o romana) y cuya asimilación en Cerdeña comenzó a finales del s. V a.C. (Garbati 2008: 22 y 83-84).
Otro problema que nos impide conocer las advocaciones de los santuarios rurales sería la superficie sacralizada pues podría comprender desde una vasta extensión de tierra hasta toda una montaña donde se habría producido una manifestación o acción de alguna(s) divinidad(es) (Lipiński 1995: 417-418 y 421-422). Así, posiblemente debido a que la instalación de un santuario no implicaba forzosamente la construcción de un edificio, la palabra qďs (Krahmalkov 2000: 425) era usada para referirse a todo lo sagrado o consagrado, al santuario, y al lugar santo. Esto explicaría que la mayor parte de santuarios rurales podían ser espacios al aire libre cuyo único testimonio serían estructuras en negativo como fosas, fauissae, bothroi o thysiae en las que se depositarían todos los objetos que se amortizarían tras los distintos exvotos y rituales (Garbati 2008: 17-18); también podían usarse cuevas o abrigos naturales entendidos como puertas de acceso al dominio de las divinidades cthonianas (Lipiński 1995: 423). En cualquiera de los casos, la falta de estructuras visibles haría una difícil identificación en el territorio y por lo tanto, debemos considerar que únicamente han sido contabilizados una minoría poco representativa de este tipo de lugares de culto. Con suerte, en algunos casos y pasado algún tiempo, tanto cuevas como santuarios al aire libre se monumentalizarían y podría indicar su dominio sobre el paisaje (Bonnet 2008: 674-675).

\section{LOS TEMPLOS RURALES, URBANOS Y LA ICO- NOGRAFÍA NUMISMÁTICA}

Para completar nuestra investigación, consideramos de utilidad realizar una confrontación entre las divinidades poliadas de los templos urbanos, las advocaciones rurales del territorio controlado desde los centros urbanos, y la iconografía de las monedas acuñadas en estas ciudades fenicias. Pese a que no disponemos de toda la información completa de las ciudades fenicias del Mediterráneo Occidental, sí que podemos extraer, gracias a los lugares donde aparecen dos o tres de las variables, algunas conclusiones de interés (fig. 6). Así, una de las primeras cuestiones que ya puso de manifiesto Mora Serrano (2013: 156) sería la coincidencia entre el templo principal cívico (o uno de ellos en algunos casos), y la iconografía de sus amonedaciones. En los raros casos en que no coincide advocación poliada e iconografía, como sería la ciudad de Caura (Escacena 2001), podemos aducir 


\begin{tabular}{|c|c|c|c|c|c|c|}
\hline \multirow[b]{2}{*}{ Polis fenicia } & \multirow{2}{*}{$\begin{array}{l}\text { Iconografía } \\
\text { monetal }\end{array}$} & \multirow[b]{2}{*}{ Cronología monetal } & \multirow{2}{*}{$\begin{array}{c}\text { Advocación templo } \\
\text { urbano }\end{array}$} & Cronología & \multirow{2}{*}{$\begin{array}{c}\text { Advocación/es santuario/s } \\
\text { rural/es }\end{array}$} & Cronología \\
\hline & & & & $\begin{array}{l}\text { Templo } \\
\text { urbano }\end{array}$ & & $\begin{array}{l}\text { Santuarios } \\
\text { rurales }\end{array}$ \\
\hline Baria & Astarté & $\begin{array}{l}\text { Tercer cuarto del s. II a.C. } \\
\text { (Mora Serrano 2013: } \\
\text { 156-157) }\end{array}$ & $\begin{array}{l}\text { Astarté (López } \\
\text { Castro 2005) }\end{array}$ & VII?-II a.C. & $\begin{array}{l}\text { Cerro Montroy: Tinnit (López } \\
\text { Castro 2004) }\end{array}$ & IV-II a.C. \\
\hline \multirow{3}{*}{ Cartago } & Niké & 410 a.C. & \multirow[b]{2}{*}{ Melqart } & & & \\
\hline & \multirow[t]{2}{*}{ Astarté } & \multirow{2}{*}{$\begin{array}{l}\text { Primera mitad del s. IV } \\
\text { a.C.-146 a.C. (Manfredi } \\
\text { 1995: 240-258) }\end{array}$} & & & & \\
\hline & & & Eshmum & & & \\
\hline \multirow[t]{2}{*}{ Carteia } & Tinnit & \begin{tabular}{|l|} 
Segunda mitad del s. I \\
a.C. (Mora Serrano 2013: \\
169 y 176) \\
\end{tabular} & \multirow{2}{*}{$\begin{array}{l}\text { Melqart? (Roldán } \\
\text { Gómez et al. 2006) }\end{array}$} & \multirow[t]{2}{*}{ IV-II a.C. } & \multirow{2}{*}{$\begin{array}{l}\text { Gorham's Cave: } \\
\text { Astarté/Tinnit (Gutiérrez } \\
\text { López et al, 2013) }\end{array}$} & \multirow[t]{2}{*}{$\begin{array}{l}\text { VIII-mediados } \\
\text { II a.C. }\end{array}$} \\
\hline & Melqart & $\begin{array}{l}\text { Finales del s. II a.C. } \\
\text { (Mora Serrano 2013: 169) }\end{array}$ & & & & \\
\hline Caura & Tinnit & $\begin{array}{l}\text { Primera mitad del siglo I } \\
\text { a.C. (García-Bellido 2001: } \\
\text { 101-102) }\end{array}$ & $\begin{array}{l}\text { Baal Shaphon } \\
\text { (Escacena 2001) }\end{array}$ & VIII-VI a.C. & & \\
\hline $\begin{array}{l}\text { Cossura } \\
\text { (Pantelería) }\end{array}$ & $\begin{array}{l}\text { Astarté/Ba alat } \\
\text { Gubal/Isis }\end{array}$ & $\begin{array}{l}\text { Finales del s. III-II a.C. } \\
\text { (Manfredi 1995: 326) }\end{array}$ & & & Astarté (Lago Venere) & IV-II a.C. \\
\hline \multirow[b]{2}{*}{ Gadir } & Melqart & III-206 a.C. & \multirow[b]{2}{*}{ Melqart } & \multirow[b]{2}{*}{ VIII-I a.C. } & \multirow[b]{2}{*}{$\begin{array}{l}\text { La Algaida: Astarté/Tinnit } \\
\text { (Ferrer Albelda 2002) }\end{array}$} & \multirow[b]{2}{*}{ VI-II a.C. } \\
\hline & Shamash & $\begin{array}{l}\text { II-I a.C. (Manfredi 1995: } \\
\text { 409-419) }\end{array}$ & & & & \\
\hline \multirow{4}{*}{ Iboshim } & \multirow{4}{*}{ Bes } & \multirow{4}{*}{$\begin{array}{l}\text { 300-75 a.C. (Manfredi } \\
1995: 382-389)\end{array}$} & & & \begin{tabular}{|l} 
Es Culleram: Tinnit (Ramon \\
1985)
\end{tabular} & V-II a.C. \\
\hline & & & & & $\begin{array}{l}\text { Cap de Llibrell: Tinnit } \\
\text { leontocéfala (Ramon 2014) }\end{array}$ & V-I a.C. \\
\hline & & & & & $\begin{array}{l}\text { Ca N'Ursul: Astartè (Gómez } \\
\text { Bellard 2008) }\end{array}$ & III-II a.C. \\
\hline & & & & & $\begin{array}{l}\text { Can Jai: Astartè (Gómez } \\
\text { Bellard 2008) }\end{array}$ & IV-III a.C. \\
\hline \multirow{2}{*}{ Lixus } & Melqart & \multirow{2}{*}{$\begin{array}{l}\text { II-I a.C. (Manfredi 1995: } \\
\text { 295-298) }\end{array}$} & \multirow{2}{*}{ Melqart } & \multirow{2}{*}{ VII-II a.C. } & & \\
\hline & Ptah & & & & & \\
\hline \multirow[t]{2}{*}{ Malaka } & $\begin{array}{l}\text { Hefestos/Phat/ } \\
\text { Reshef }\end{array}$ & \multirow[t]{2}{*}{$\begin{array}{l}\text { Finales del s. III- II a.C. } \\
\text { (García-Bellido 2001: } \\
\text { 274-278) }\end{array}$} & \multirow[t]{2}{*}{$\begin{array}{l}\text { Templo del teatro: } \\
\text { Astarté-Tinnit } \\
\text { (López Castro y } \\
\text { Mora Serrano 2002) }\end{array}$} & \multirow[t]{2}{*}{ IV-II a.C. } & & \\
\hline & Tinnit & & & & & \\
\hline \multirow{2}{*}{ Onoba } & \begin{tabular}{|l|} 
Cabeza \\
masculina
\end{tabular} & \multirow{2}{*}{$\begin{array}{l}\text { I a.C. (García-Bellido } \\
\text { 2001: 301-302) }\end{array}$} & \multirow{2}{*}{$\begin{array}{l}\text { Melqart (Ferrer } \\
\text { Albelda e.p.) }\end{array}$} & & & \\
\hline & \begin{tabular}{|l|} 
Cabeza \\
femenina
\end{tabular} & & & & & \\
\hline Malta & Astarté & $\begin{array}{l}\text { Finales del III-inicios del } \\
\text { Il a.C. (Manfredi 1995: }\end{array}$ & $\begin{array}{l}\text { Tas Silg: Astarté } \\
\text { (Amadasi Guzzo }\end{array}$ & VIII-I a.C. & & \\
\hline & $\begin{array}{l}\text { Eshmun/Baal } \\
\text { Hamon }\end{array}$ & 203 y 325$)$ & $2010)$ & & & \\
\hline Utica & $\begin{array}{l}\text { Dioscuros } \\
(\check{S} h r \text { y } \breve{S} l m ?)\end{array}$ & $\begin{array}{l}\text { II a.C. (Manfredi 1995: } \\
\text { 281) }\end{array}$ & $\begin{array}{l}\text { Baal Hamon? } \\
\text { (López Castro et al. } \\
\text { 2016) }\end{array}$ & VII-II a.C. & & \\
\hline
\end{tabular}

Fig. 6: Tabla con la inconografía monetaria, advocaciones cívicas y rurales de algunas poleis fenicias. 


\begin{tabular}{|c|c|c|}
\hline Tipo & Nombre & Advocación \\
\hline \multirow{2}{*}{$\begin{array}{l}\text { Santuario en } \\
\text { cueva nautico }\end{array}$} & $\begin{array}{l}\text { Gorham's Cave (Gutiérrez López } \\
\text { et al. 2013) }\end{array}$ & Astarté-Tinnit? \\
\hline & $\begin{array}{l}\begin{array}{l}\text { Grotta del Pozzo (Fabignana) } \\
\text { (Rocco 1972) }\end{array} \\
\end{array}$ & Melqart? \\
\hline \multirow{6}{*}{$\begin{array}{l}\text { Santuario rural } \\
\text { al aire libre }\end{array}$} & $\begin{array}{l}\text { Banatou (Cerdeña) (Van } \\
\text { Dommelen 1998) }\end{array}$ & Astarté \\
\hline & $\begin{array}{l}\text { Cerro do Forte (De Mello Beirao } \\
\text { et al. 1985) }\end{array}$ & Tinnit? \\
\hline & $\begin{array}{l}\text { Madonna del Rimedio (Barreca } \\
\text { 1988) }\end{array}$ & Astarté \\
\hline & $\begin{array}{l}\text { Matta Sterri (Van Dommelen } \\
\text { 1998) }\end{array}$ & Astarté \\
\hline & \begin{tabular}{|l|} 
Mogador (López Pardo y \\
Mederos 2008) \\
\end{tabular} & Astarté \\
\hline & $\begin{array}{l}\text { Monte Benei (Van Dommelen } \\
1998 \text { ) }\end{array}$ & Astarté \\
\hline \multirow{13}{*}{$\begin{array}{l}\text { Santuario rural } \\
\text { construido }\end{array}$} & Antas (Barreca 1988) & Sid \\
\hline & $\begin{array}{l}\text { Ca N'Ursul (Gómez Bellard } \\
\text { 2008) }\end{array}$ & Astarté \\
\hline & Can Jai (Gómez Bellard 2008) & Astarté \\
\hline & Cap de Llibrell (Ramon 2014) & \begin{tabular}{|l|} 
Tinnit \\
leontocéfala
\end{tabular} \\
\hline & $\begin{array}{l}\text { El Carambolo (Fernández Flores } \\
\text { y Rodriguez Azogue 2010) }\end{array}$ & Astarté y Baal \\
\hline & La Algaida (Ferrer Albelda 2002) & Astarté-Tinnit \\
\hline & $\begin{array}{l}\text { Nuraghe Tunis (van Dommelen } \\
1998 \text { ) }\end{array}$ & Astarté \\
\hline & $\begin{array}{l}\text { Peñón de Salobreña (Arteaga et } \\
\text { al. 1992) }\end{array}$ & Tinnit \\
\hline & $\begin{array}{l}\text { Promunturium Iunonis (Ferrer } \\
\text { Albelda e.p.) }\end{array}$ & Astarté astral \\
\hline & \begin{tabular}{|l} 
San Nicolò Guerrei (Barreca \\
1988)
\end{tabular} & Eshmun \\
\hline & Santa Cristina (Barreca 1988) & Astarté \\
\hline & \begin{tabular}{|l|} 
Santa Margherita di Pula (Barreca \\
1988)
\end{tabular} & Astarté \\
\hline & Terreseu (Barreca 1988) & Astarté \\
\hline \multirow{3}{*}{$\begin{array}{l}\text { Santuario rural } \\
\text { en cueva }\end{array}$} & $\begin{array}{l}\text { Cerro Montroy (López Castro } \\
\text { 2004) }\end{array}$ & Tinnit \\
\hline & Es Culleram (Ramon 1985) & Tinnit \\
\hline & Grotta Regina (Bisi 1969) & Tinnit? \\
\hline
\end{tabular}

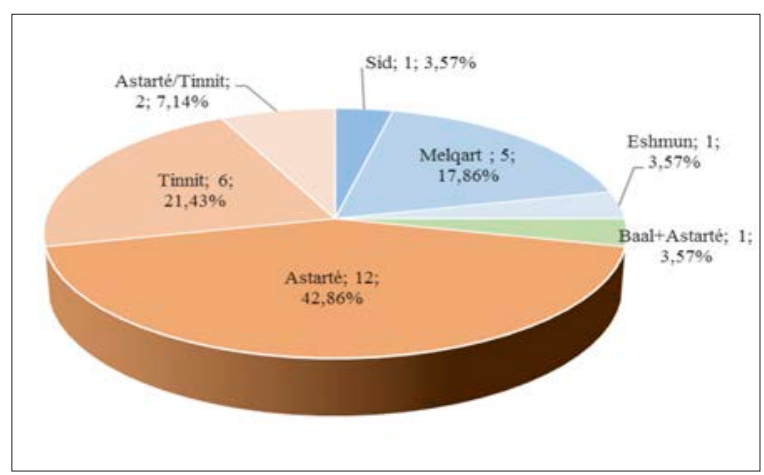

Fig. 7: Tabla y gráfico con los lugares de culto rurales fenicios en los que se conoce advocación.

dataciones alejadas entre sí entre el templo documentado (VIII-VI a.C.) y las acuñaciones (I a.C.). Por otro lado, la falta de coincidencia entre las divinidades rurales y las advocaciones cívicas nos permite suponer que no sería el templo principal el que llevaría a cabo la colonización agrícola como hasta ahora se había planteado (Alvar y González Wagner 1988: 174-176; Arteaga 1994: 32) sino que sería un proceso independiente donde los santuarios rurales jugarían otro tipo de papel económico en los territorios fenicios. El mejor ejemplo sería Ibiza, donde la gruta natural d'Es Culleram se ha relacionado con un programa de implantación agrícola que se llevaría a cabo desde la ciudad de Iboshim y que marcaría la proyección política, territorial y económica de la ciudad (Marín Ceballos et al. 2010: 155) pero cuyo dios principal, Bes, según la iconografía monetaria, no estaría presente en ninguno de los santuarios rurales identificados en la isla.

Finalmente, podemos advertir una mayor representación cultual de divinidades femeninas en los santuarios rurales o extraurbanos (fig. 7), y su implantación coincidiría con los cambios económicos y religiosos a partir del s. IV a.C. cuyo mejor exponente encontramos en Cartago. De este modo, frente a 14 lugares de culto rurales bajo la tutela de Astarté o Tinnit, sólo tres estarían dedicados a dioses masculinos y uno de ellos, por su posición costera, estaría ligado a la navegación más que a la explotación de los recursos territoriales.

\section{CONCLUSIONES}

Aunque no es en absoluto novedosa, una de las primeras conclusiones que podemos extraer sobre la religión rural fenicia es el fuerte componente agropecuario de los ritos, celebraciones y atribuciones religiosas de los dioses principales. La vinculación con la fertilidad de la tierra, la fecundidad de los rebaños, la explotación del territorio, o los fenómenos meteorológicos, constituyeron las principales preocupaciones de una sociedad eminentemente rural. Es por ello por lo que la adaptación y evolución de las divinidades y sus atributos en Occidente dependió en gran medida de estas cualidades en las que también se vieron envueltas la interacción con los autóctonos y la propia idiosincrasia de las antiguas colonias fenicias a lo largo del I milenio a.C. Por otro lado, fueron precisamente las divinidades cuyos rituales estuvieron vinculados con la fertilidad de la tierra, las que mayor acogida y difusión tuvieron entre los santuarios rurales y que supusieron una verdadera fuente de aculturación para las poblaciones nativas. 
Sabemos también que, durante los primeros momentos de colonización, la apropiación y explotación territorial estuvo unida a la sacralización de espacios bajo la tutela mayoritariamente de dioses masculinos, especialmente Melqart, pero también Baal. En contraposición a ello, el inicio de la explotación sistemática de los territorios fenicios a partir del s. V a.C., está indisolublemente ligado a la implantación de espacios cultuales rurales bajo advocaciones agropecuarias por excelencia. Los datos que nos ofrecen estos lugares sobre los dioses tutelares nos indican un claro predominio de deidades femeninas, Tinnit o Astarté, cuyas representaciones figuradas, en la mayor parte de los casos, portarían elementos agrícolas o ganaderos. Además, en los pocos casos en los que conocemos las divinidades poliadas y los cultos rurales asociados al territorio de la ciudad principal, hemos comprobado cómo existe una divergencia entre las advocaciones cívicas y las rurales. Ello nos hace suponer que en la mayoría de los casos no sería el templo principal el que llevaría a cabo la de implantación territorial, sino que serían otro tipo de instituciones ciudadanas o, incluso la élite como empresa privada, las que gestionarían la explotación de los recursos naturales.

\section{NOTA}

1. Como también se advierte en este trabajo, se ha propuesto el patronazgo de Baal Hammon en Antas (vid. Roobaert 1986) y aparece mencionado en los grafitos de Grotta Regina, «que sea bendecido por el señor $b$ ' $l$ " ", fechados entre los ss. V y I a.C. (Bisi 1969: 8-9, 13-17, 30-31, 37, 49 y 58).

\section{BIBLIOGRAFÍA}

ALMAGRO GORBEA, M. J. (1983): Un depósito votivo de terracotas de Villaricos, Homenaje al profesor Martín Almagro Basch, Vol.II, Madrid, 291-307.

AMADASI GUZZO, M. G. (2005): Cultes et épithètes de Milqart, Transeuphratène 30, 9-18.

AMADASI GUZZO, M. G. (2010): Notes sur quelques divinités phéniciennes en pays étranger, Carthage et les autochtones de son empire du temps de Zama: colloque international organisé à Siliana et Tunis du 10 au 13 mars 2004 par l'Institut National du Patrimoine et l'Association de sauvegarde du site de Zama: Hommage à Mhamed Hassine Fantar (A. Ferjaoui, coord.), Tunis, 65-69.

ALVAR, J.; GONZÁLEZ WAGNER, C. (1988): La actividad agrícola en la economía fenicia de la Península Ibérica, Gerión 6, 169-185.
ANGÁS PAJAS, J. (2005): Santuarios como indicadores de fronteras en el territorio noroccidental de Vulci (siglos VII-III a.C. Italia Centro-Tirrénica), Saldvie 5, 65-94.

ARRUDA, A. M.; CELESTINO PÉREZ S. (2009): Arquitectura religiosa en Tartessos, Santuarios, oppida y ciudades: arquitectura sacra en el origen y desarrollo urbano del Mediterráneo Occidental (P. Mateos, S. Celestino, A. Pizzo, T. Tortosa, eds.). Anejos de AEA 45, Madrid, 29-77.

ARTEAGA, O. (1994): La Liga Púnica Gaditana. Aproximación a una visión histórica occidental, para su contrastación con el desarrollo de la hegemonía cartaginesa, en el mundo mediterráneo, Cartago, Gadir, Ebusus y la influencia púnica en los territorios hispanos. VIII Jornadas de Arqueología Fenicio-púnica (Ibiza, 1993), Trabajos del Museo Arqueológico de Ibiza 33, Ibiza, 23-57.

ARTEAGA, O.; NAVAS, J.; RAMOS MUÑOZ, J. F.; ROOS, A. M. (1992): Excavación de urgencia en el Peñón de Salobreña (Granada), Salobreña.

AUBET, M. E. (1969): La cueva d'Es Cuyram (Ibiza), Barcelona.

BARRECA, F. (1969): Lo scavo del tempio, Ricerche puniche ad Antas. Rapporto preliminare della Missione archeologica dell'Università di Roma e della Soprintendenza alle Antichità di Cagliari, Studi Semitici 30, Roma, 9-46.

BARRECA, F. (1988): La civiltà fenicio-punica in Sardegna. Studi e Monumenti 3, Sassari.

BARTOLONI, P. (2000) : Il santuario di Su Campu 'e Sa Domu, Donum Natalicium. Studi in onore di Claudio Saporetti in occasione del suo $60^{\circ}$ compleanno (P. Negri Scafa y P. Gentili, eds.), Roma, 13-22.

BELTRÁN, A.; COSTA, B.; FERNÁNDEZ, J. H. (1987): Las pinturas rupestres de «Sa Cova des Vi», Ses Fontanelles, Sant Antoni de Portmany (Ibiza), Trabajos del Museo Arqueológico de Ibiza 17, Ibiza.

BEN YOUNES, H. (1995): Les ensembles funéraires préromains de Henchir el-Alia au Sahel tunisien, Africa 13, 27-50.

BERCHEM, D. V. (1967): Sanctuaires d'Hercule-Melqart. Contribution à l'étude de l'expansion phénicienne en Méditerranée, Syria 44, Fasc. 1/2, 73-109.

DOI: https://doi.org/10.3406/syria.1967.5979

BERNARDINI, P. (2012-2013): Organized Settlements and Cult Places in the Phoenician Western Expansion between the 9th and 7th Centuries BCE. A Reflection on the Tophet, Richerche storiche e filologiche sulle culture del Vicino Oriente e del Mediterraneo antico (P. Xella, ed.), Studi Epigrafici e Linguistici sul Vicino Oriente antico. Nouva Serie 29-30, Roma, 1-22.

BISI, A. M. (1969): Lo scavo del 1969, Grotta Regina-I. Rapporto preliminare della Missione congiunta con la Soprintendeza alla Antichità della Sicilia Occidentale, Studi Semitici 33, Roma, 7-37.

BONNET, C. (1988): Melqart. Cultes et mythes de l'Héraclès tyrien en Méditerranée, Studia Phoenicia VIII, Leuven. 
BONNET, C. (1991): Tinnit, soeur cadette d'Astarté?, WO XXII, 73-84.

BONNET, C. (1996): Astarté. Dossier documentaire et perspectives historiques, Contributi alla Storia della Religione FenicioPunica II, Roma.

BONNET, C. (2005): Melqart in Occidente. Percorsi di appropriazione e de acculturazione, Il Mediterraneo di Herakles. Studi e ricerche (P. Bernardini, P. Zucca, eds.), Roma, 17-28

BONNET, C. (2008): Dove vivono gli dei? Note sulla terminologia fenicio-punica dei luoghi di culto e sui modi di rappresentazione del mondo divino, Saturnia Tellus. Definizioni dello spazio consacrato in ambiente etrusco, italico, feniciopunico, iberico e celtico. Atti del Convengo Internazionale svoltosi a Roma dal 10 al 12 novembre 2004 (X. Dupré Raventós, S. Ribichini, S. Verger, eds), Roma, 673-685.

BUHAGIAR, M. (1988): Two archaeological sites-Ras Ir-Raћeb, Malta, and Ras Il Wardija, Gozo, Melita Historica, New Series 10/1, 69-87.

BUNNENS, G. (1986): Aspects religieux de l'expansion phénicienne, Religio phoenicia. Acta Colloquii Namurcensismhabiti diebus 14 et 15 mensis Decenbris anni 1984 (C. Bonnet, E. Lipinski y P. Marchetti, eds.). Studia Phoenicia IV, Namur, 119-125.

BREUIL, H. (1920): Cueva de las Fontanellas (Iviça), Boletín de la Real Sociedad Española de Historia Natural XX, 370-373.

CAQUOT, A. (1963): Les danses sacrées en Israël et à l'entour, Les danses sacrées. Égypte Ancienne-Israël- Islam- Asie Centrale-Inde-Cambodge-Bali-Java-Chine-Japon, Sources Orientales VI, Paris, 120-143

CRUCCAS, E. (2015): The Urban and Rural Landscapes in Punic and Roman northwest Sardinia: persistences, cultural interactions and rituals, Analysis archaeologica. An International Journal of Western Mediterranean Archaeology 1, 87101.

DELCOR, M. (1970): Rites pour l'obtention de la pluie à Jérusalem et dans le Proche-Orient, RHR 178-2, 117-132. DOI: https://doi.org/10.3406/rhr.1970.9645

DELCOR, M. (1976): Astarté et la fécondité des troupeaux en Deut. 7,13 et parallèles, Religion d'Israël et Proche Orient Ancien, Leiden, 86-94.

DE MELLO BEIRĀO C.; TAVARES DA SILVA C.; SOARES J.; VARELA GOMES M.; VARELA GOMES R. (1985): Depósito votivo da II Idade do Ferro de Garvāo. Notícia da primeira campanha da escavações, O Arqueologo Portugês, Serie IV/3, 45-136.

DOMINGUEZ MONEDERO, A. (1995): Religión, rito y ritual durante la protohistoria peninsular. El fenómeno religioso en la cultura ibérica, Ritual, Rites and Religion in Prehistory. IIIrd Deya International Conference of Prehistory (W. H. Waldren, J. A. Ensenyat, R. C. Kennard, eds.). Vol. II. BAR International Series 611, Oxford, 21-91.

DUSSAUD, R. (1921): Les origines cananéennes du Sacrifice Israélite, Paris.
ESCACENA, J. L. (2001): Fenicios a las puertas de Tartessos, Complutum 12, 73-96.

FANTAR, M. H. (2008): Le culte de Déméter et ses incidences à Carthage, Demetra. La divinità, $i$ santuari, il culto, la leggenda. Atti del I Congresso Internazionale. Enna, 1-4 Luglui 2004 (C.A. di Stefano, ed.), Biblioteca di «Sicilia Antiqua» 2, Pisa-Roma, 243-246.

FERRER ALBELDA E. (2002): Topografía sagrada de Extremo Occidente: santuarios, templos y lugares de culto de la Iberia púnica, Ex Oriente Lux: las religiones orientales antiguas en la Península Ibérica (Ferrer Albelda E., ed.), Spal Monografías II, Sevilla, 185-217.

FERRER ALBELDA, E. (2014): Ruptura y continuidad en las manifestaciones religiosas púnicas de Iberia (siglos III-I a.C.), Diálogo de Identidades. Bajo el prisma de las manifestaciones religiosas en el ámbito mediterráneo (s. III a.C.-s. I d. C.). Reunión científica, Mérida (Badajoz, España), 1214 de noviembre, 2012 (T. Tortosa, ed.). Anejos de AEA LXXII, Mérida, 219- 250.

FERRER ALBELDA, E. (2015): El “signo de Tanit” en la Península Ibérica, Orientalística en tiempos de crisis. Actas del VI Congreso Nacional del Centro de Estudios del Próximo Oriente (A. Bernabé, J.A., Álvarez-Pedrosa, eds.), Zaragoza, 167-179.

FERRER ALBELDA, E. (2017): El poblamiento en el Irr milenio a.C.: Baesippo y su territorio, Arqueología de Vejer. De la Prehistoria a época andalusí, Sevilla, 55-94.

GARBATI, G. (2008): Religione votiva. Per un'interpretazione storico-religiosa delle terracotte votive nella Sardegna punica e tardo-punica, Pisa-Roma.

GARBATI, G. (2012-2013): Baal Hammon and Tinnit in Carthage. The Tophet between the Origin and the Expansion of the Colonial World, Richerche storiche e filologiche sulle culture del Vicino Oriente e del Mediterraneo antico (P. Xella, ed.), Studi Epigrafici e Linguistici sul Vicino Oriente antico. Nouva Serie 29-30, Roma, 49-64.

GARBATI, G. (2014-2015): La dea "Sfuggente". (Ancora) su Demetra in Sardegna alla luce di alcune ricerche recenti, Byrsa, 25-26/2014 y 27-28/2015, 81-113.

GARCÍA-BELLIDO, M. P. (1991): Las religiones orientales en la Península Ibérica: documentos numismáticos I, AEA 64, 37-81.

DOI: https://doi.org/10.3989/aespa.1991.v64.498

GARCÍA-BELLIDO, M. P. (2001): Diccionario de cecas y pueblos hispánicos: con una introducción a la numismática antigua de la Península Ibérica. Vol. 2. Catálogo de cecas y pueblos que acuñan moneda, Madrid.

GÓMEZ BELLARD, C. (2008): Espacios sagrados en la Ibiza púnica, Saturnia Tellus. Definizioni dello spazio consacrato in ambiente etrusco, italico, fenicio-punico, iberico e celtico. Atti del Convegno Internazionale svoltosi a Roma dal 10 al 12 novembre 2004 (X. Dupré, S. Ribichini, S. Verger, eds.), Roma, 119-132. 
GÓMEZ BELLARD, C.; VIDAL GONZÁLEZ, P. (2000): Las cuevas-santuario fenicio-púnicas y la navegación en el Mediterráneo, Santuarios fenico-púnicos en Iberia y su influencia en los cultos indígenas. XIV Jornadas de arqueología fenicio-púnicas (Eivissa, 1999) (J. H. Fernández, B. Costa, coords.), Treballs del Museu Arqueològic d'Eivissa i Formentera 46, 103-145.

GROTANELLI, C. (1981): Santuari e divinitá delle colonie d'Occidente, La religione fenicia. Matrici Orientali $e$ sviluppi occidentali. Atti del Colloquio en Roma, Roma, 109-133.

GUTIÉRREZ LÓPEZ J. M.; REINOSO, M. C.; GILES PACHECO F.; FINLAYSON C.; SÁEZ ROMERO A. (2013): La cueva de Gorham (Gibraltar): un santuario fenicio en el confín occidental del Mediterráneo, Confines. El extremo del mundo durante la Antigüedad (F. Prados, I. García, G. Bernard, eds.), Alicante, 303-381.

HACHUEL, E.; MARÍ, V. (1988): El santuario de la Illa Plana (Ibiza). Una propuesta de análisis, Ibiza,

HORN, F. (2011): Ibères, grecs et puniques en Extrême-Occident. Les terres cuites de l'espace ibérique du VIII ${ }^{e}$ au II ${ }^{e}$ siècle av. J.-C., Madrid.

HOURS-MIEDAN, M. (1951): Les représentations figurées sur les stèles de Carthage, Cahiers de Byrsa 1, 15-160.

HVIDBERG-HANSEN, F. O. (1986): Uni-Ashtarte and Tanit-Iuno Caelestis. Two Phoenician goddesses of fertility reconsidered from recent archaeological discoveries, Archaeology and Fertility Cult in the Ancient Mediterranean: First International Conference on Archaeology of the Ancient Mediterranean, University of Malta, 2-5 September 1985 (A. Bonanno, ed.), Malta, 170-224.

JOURDAIN-ANNEQUIN, C. (1992): Héraclès en Occident, Héraclès d'une rive à l'autre de la Mediterranée. Bilan et perspectives. Actes de la table ronde de Rome, Academia Belgica-École Française de Rome, 15-16 septembre 1989 à l'Occasion du cinquantenaire de l'Academia Belgica en Hommage à Franz Cumont, son Prémier Présidente (C. Bonnet, C. JourdainAnnaquin, eds.), Bruxelles-Rome, 263-291.

KRAHMALKOV, C. R. (2000): Phoenician-Punic Dictionary, Lovaina.

LAGRANGE, M. J. (1905): Études sur les religions sémitiques, Paris.

LANCELLOTI, M. G. (2010): Dea Caelestis. Studi e Materiali per la storia di una divinità dell'Africa Romana, Collezione di Studi Fenici 44, Pisa-Roma.

LÓPEZ CASTRO, J. L. (2004): Un santuario rural en Baria (Villaricos-Almería), Actas II Congreso Internacional del Mundo Púnico. El mundo púnico. Religión, Antropología y Cultura Material. Cartagena, 6-9 de abril de 2000 (A. González Blanco, G. Matilla Séiquer, A. Egea Vivancos, eds.), Murcia, 77-89.

LÓPEZ CASTRO, J. L. (2005): Astarté en Baria. Templo y producción entre los fenicios occidentales, AEA 78, 5-21. DOI: https://doi.org/10.3989/aespa.2005.v78.71
LÓPEZ CASTRO, J. L.; MORA SERRANO, B. (2002): Malaka y las ciudades fenicias en el Occidente Mediterráneo. Siglos VI a.C.- I d.C., Tema Monográfico. Colonizadores e Indígenas en la Península Ibérica, Mainake 24, 181-204.

LÓPEZ CASTRO, J. L.; FERJAOUI, A.; FERRER, E.; PARDO, I.; BEN, I.; PEÑA, V. (2016): Edificios monumentales fenicio-púnicos en Útica, Aula Orientalis 34-2, 265-292.

LÓPEZ GARÍ, J. M.; MARLASCA, R.; ESCANDELL, M. J. (2014): El yacimiento de es Rafal (Puig d'en Valls, Eivissa) y dos pebeteros en forma de cabeza femenina, Imagen y culto en la Iberia Prerromana II: nuevas lecturas sobre los pebeteros en forma de cabeza femenina (M. C. Marín Ceballos, A. M. Jiménez Flores, coords.), Spal Monografías XVIII, Sevilla, 61-83.

LÓPEZ PARDO, F.; MEDEROS, A. (2008): La factoría fenicia de la isla de Mogador y los pueblos del Atlas, Tenerife.

LIPINSKI, E. (1993): Rites et sacrifices dans la tradition phénico-punique, Ritual and Sacrifice in the Ancient Near East. Proceedings of the International Conference organized by the Katholieke Universiteit Leuven from the 17th to the 20th of April 1991 (J. Quaegebeur, ed.), Lovaina, 257- 281.

LIPINSKI, E. (1995): Dieux et déesses de l'univers phénicien et punique, Studia phoenicia XIV, Lovaina.

MANFREDI, L. I. (1995): Monete puniche. Repertorio epigrafico e numismatico delle leggende puniche, Bollettino di Numismatica, Monografia 6, Roma.

MANFREDI, L. I. (2003): La politica amministrativa di Cartagine in Africa, Atti della Accademia Nazionale dei Lincei Serie 9, vol. XVI, fascicolo 3, Roma, 324-532.

MARÍN, M. C.; BELÉN, M.; JIMÉNEZ, A. M. (2010): El proyecto de estudio de los materiales de la cueva de Es Culleram, Mainake 32/1, 133-157.

MARÍN, M. C.; JIMÉNEZ, A. M.; BELÉN, M.; FERNÁNDEZ, J. H.; HORN, F.; MEZQUIDA, A. (2015): Les terres cuites de la grotte d'Es Culleram (Ibiza, Espagne): iconographie et fonction, Archaiologia. Figurines grecques en contexte. Présence muette dans le sanctuaire la tombe et la maison (S. Huysecom, A. Muller, dirs.), Villeneuve d'Ascq, 199- 217.

MORA, B. (2013): Iconografía monetal fenicio-púnica como reflejo de los cultos cívicos, mitos e identidades compartidas, $\mathrm{La}$ moneda y su papel en las sociedades fenicio-púnicas. XXVII Jornadas de Arqueología fenicio-púnica (B. Costa, J. H. Fernández, eds.), Eivissa, 143-182.

MORET. A. (1935): Rituels agraires de l'ancien Orient à la lumière des nouveaux textes de Ras Shamra, Annuaire de l'Institut de Philologie et d'Histoire Orientales III, 311-342

MUÑOZ GAMBERO, J. M. (1996): El cerro de la Tortuga, Economía y sociedad rural fenicia en el Mediterráneo Occidental. Congreso de Historia Antigua de Málaga y su Provincia (F. Wulff Alonso, G. Cruz Andreotti, eds.), Málaga, 221-243. 
NORTH, J. A. (1995): Religion and rusticity, Urban Society in Roman Italy (T. J. Corenell, K. Lomas, eds), London, 135-150.

OGGIANO, I. (2005): Dal terreno al divino. Archeologia del culto nella Palestina del primo millennio, Roma.

PARDO BARRIONUEVO, C. A. (2015): Economía y sociedad rural fenicia en el Mediterráneo Occidental, Sevilla.

PARDO BARRIONUEVO, C. A. (e.p.): Sacrificios rituales y ofrendas de alimentos en los lugares de culto fenicios.

PRADOS MARTINEZ, F. (2008): Arquitectura púnica. Los monumentos funerarios, Anejos de AEA XLIV, Madrid.

RAMON TORRES J. (1985): Es Cuieram 1981, Noticiario Arqueológico Hispánico 20, 225-256.

RAMON TORRES, J. (1995) : Ses Païsses de Cala d'Hort. Un establiment rural d'època antiga al sud-oest d'Eivissa, Quaderns d'Arqueologia Pitiüsa 1, Ibiza.

RAMON TORRES J. (2014): Le sanctuaire punique du Cap de Librell (Ibiza). Un point du guet et un amer pour la navigation côtière autour d'Ebusus, Actes des XXXIV rencontres Internationales d'Archéologie et d'Histoire d'Antibes. Implantations humaines en milieu littoral Méditerranéen: facteurs d'installation et processus d'appropriation de l'espace (Préhistoire, Antiquité, Moyen Âge) (L. Mercuri, R. González Villaescusa, B. Fréderique, dirs.), Antibes, 243-252.

RIBICHINI, S. (1985): Poenus advena. Gli fenici e l'interpretazione classica, Roma.

RIBICHINI, S. (1986): Agrouheros, Baal Addir et le Pluton Africain, Actes du III Colloque sur l'histoire et l'archéologie de l'Afrique du Nord (Montpellier), Paris, 133-140.

RIBICHINI, S. (2008): Mytes et rites des phéniciens et des carthaginois, Mythologie et religion des sémites occidentaux. Vol. II. Émar, Ougarit, Israël, Phénicie, Aram, Arabie (G. del Olmo Lete, ed.), Leuven-Paris, 265-376.

ROCCO B. (1972): La grotta del Pozzo a Favignana, Sicilia Archeologica 17 (Marzo 1972), Anno V, 9-20.

ROLDÁN, L.; BENDALA, M.; BLÁNQUEZ, J.; MARTÍNEZ, S. (2006): Estudio Histórico-Arqueológico de la Ciudad de Carteia (San Roque, Cádiz), 1994-1999. Vol. I, Arqueología Monografías 24, Madrid.

ROOBAERT, A. (1986): Șid, Sardus Pater ou Baal Hammon? À propos d'un bronze de Genoni (Sardaigne), Religio phoenicia. Acta Colloquii Namurcensismhabiti diebus 14 et 15 mensis Decenbris anni 1984 (C. Bonnet, E. Lipinski, P. Marchetti, eds.), Studia Phoenicia IV, Namur, 333-345.

ROPPA, A. (2013): Comunità urbane e rurali nella Sardegna punica di età ellenistica, Saguntum extra 14, Valencia.

RUIZ CABRERO, L.; PEÑA ROMO, V. (2010): La pervivencia de los tofet como elemento de cohesión territorial tras la caída de Cartago, Carthage et les autochtones de son empire du temps de Zama: colloque international organisé à Siliana et Tunis du 10 au 13 mars 2004 par l'Institut National du Patrimoine et l'Association de sauvegarde du site de Zama: Hommage à Mhamed Hassine Fantar (A. Ferjaoui, coord.), Tunis, 459-470.
RUIZ DE ARBULO BAYONA, J. (1997): Santuarios y comercio marítimo en la Península Ibérica durante la época arcaica, CPAC 18, 517-535.

SERVAIS-SOYEZ, B. (1986): La «triade» phénicienne aux époques hellénistique et romaine, Religio phoenicia. Acta Colloquii Namurcensismhabiti diebus 14 et 15 mensis Decenbris anni 1984 (C. Bonnet, E. Lipinski, P. Marchetti, eds.), Studia Phoenicia IV, Namur, 347-360.

SMITH, W. R. (1927): Lectures on the Religion of the Semites. The Fundamental Institutions, London.

TEJERA, A.; CHÁVEZ TRISTÁN, M. E. (2010): El signo de Tanit y la religión de los libios. Una hipótesis interpretativa, Carthage et les autochtones de son empire du temps de Zama: colloque international organisé à Siliana et Tunis du 10 au 13 mars 2004 par l'Institut National du Patrimoine et l'Association de sauvegarde du site de Zama: Hommage à Mhamed Hassine Fantar (A. Ferjaoui, coord.), Tunis, 295-309.

VAN DOMMELEN, P. (1998): On Colonial Grounds. A Comparative Study of Colonialism and Rural Settlement in First Millennium BC West Central Sardinia, Leiden.

VAN DOMMELEN, P. (2006): Punic farms and Carthaginian colonists: surveying punic rural settlement in the Central Mediterranean, Journal of Roman Archaeology 19/1, 7-28. DOI: https://doi.org/10.1017/S1047759400006243

VAN DOMMELEN, P.; GÓMEZ BELLARD, C. (2008a): Defining the Punic World and its Rural Contexts, Rural Landscapes of the Punic World (P. van Dommelen, C. Gómez Bellard, eds.). Monographs in Mediterranean Archaeology 11, London, 1-22.

VAN DOMMELEN, P.; GÓMEZ BELLARD, C. (2008b): Agrarian Landscapes and Rural Communities, Rural Landscapes of the Punic World (P. van Dommelen, C. Gómez Bellard, eds.). Monographs in Mediterranean Archaeology 11, London, 202-230.

VAN DOMMELEN, P.; FINOCCHI, S. (2008): Sardinia: Divergent Landscapes, Rural Landscapes of the Punic World (P. van Dommelen, C. Gómez Bellard, eds.). Monographs in Mediterranean Archaeology 11, London, 159-201.

VAN DOMMELEN, P.; LÓPEZ BERTRÁN, M. (2013): Hellenism as subaltern practice: rural cults in the Punic World, The Hellenistic West. Rethinking the Ancient Mediterranean (J. R. W. Prag, J. C. Quinn, eds.), Cambridge, 273-299. DOI: https://doi.org/10.1017/CBO9781139505987.010

XELLA, P. (1982): Gli antenati di Dio. Divinità e miti della tradizione di Canaan, Essedue.

XELLA, P. (1986): Le polythéisme phénicien, Religio phoenicia. Acta colloquii Namurcensis habiti diebus 14 et 15 mensis decembris anni 1984 (C. Bonnet, E. Lipińsky, P. Marchetti, eds.), Studia Phoenicia IV, Namur, 20-39.

XELLA, P. (1991): Baal Hamon. Recherches sur l'identité et l'histoire d'un dieu phénico-punique (Contributi alla storia della Religione Fenicio-Punica-I), Roma. 
XELLA, P. (2001a): Le soi-disant «Dieu qui meurt» en domaine phénico-punique, Transeuphratène 22, 63-77.

XELLA, P. (2001b): Da Baal di Ugarit agli dei Fenici. Una questione di vita o di morte, Quando un dio muore. Morti e Assenze divine nelle antiche tradizioni mediterranee (P. Xella, ed.), Verona, 76-97.

XELLA, P. (2012-2013): “Tophet”. An Overall Interpretation, $R i$ cherche storiche e filologiche sulle culture del Vicino Oriente e del Mediterraneo antico (P. Xella, ed.), Studi
Epigrafici e Linguistici sul Vicino Oriente antico. Nouva Serie 29-30, 259-281.

ZAMORA, J. A. (2000): La vid y el vino en Ugarit, Madrid.

ZAMORA, J. A. (2005): Jugo de cepas, sangre de uvas: la viticultura y la vinificación en el antiguo Oriente Próximo, Actas del 1 Congreso Sobre Etnoarqueología del Vino. Bullas, 4-6 Noviembre 2004, Revista Murciana de Antropología 12, 69-99.

ZUCCA, R. (1989): Il Tempio di Antas, Sardegna Archeologica. Guide e Itinerari 11, Sassari. 